\title{
Three-Dimensional Automated Crystal Orientation and Phase Mapping Analysis of Epitaxially Grown Thin Film Interfaces by Using Transmission Electron Microscopy
}

\author{
Chang-Yeon Kim ${ }^{1,2}$, Ji-Hyun Lee, ${ }^{2,3}$, Seung Jo Yoo ${ }^{2}$, Seok-Hoon Lee ${ }^{2}$, Jin-Gyu Kim ${ }^{2, *}$ \\ ${ }^{1}$ Gangneung Center, Korea Basic Science Institute, Gangneung 25457, Korea \\ ${ }^{2}$ Division of Electron Microscopic Research, Korea Basic Science Institute, Daejeon 34133, Korea \\ ${ }^{3}$ School of Semiconductor and Chemical Engineering, Chonbuk National University, Jeonju 54896, Korea
}

*Correspondence to:

Kim JG,

Tel: +82-42-865-3961

Fax: +82-42-865-3939

E-mail: jjintta@kbsi.re.kr

Received September 3, 2015

Revised September 10, 2015

Accepted September 10, 2015

\begin{abstract}
Due to the miniaturization of semiconductor devices, their crystal structure on the nanoscale must be analyzed. However, scanning electron microscope-electron backscatter diffraction (EBSD) has a limitation of resolution in nanoscale and high-resolution electron microscopy (HREM) can be used to analyze restrictive local structural information. In this study, three-dimensional (3D) automated crystal orientation and phase mapping using transmission electron microscopy (TEM) (3D TEM-EBSD) was used to identify the crystal structure relationship between an epitaxially grown $\mathrm{CdS}$ interfacial layer and a $\mathrm{Cu}\left(\operatorname{In}_{\mathrm{x}} \mathrm{Ga}_{\mathrm{x}-1}\right)$ $\mathrm{Se}_{2}$ (CIGS) solar cell layer. The 3D TEM-EBSD technique clearly defined the crystal orientation and phase of the epitaxially grown layers, making it useful for establishing the growth mechanism of functional nano-materials.
\end{abstract}

Key Words: $\mathrm{Cu}\left(\operatorname{In}_{\mathrm{x}} \mathrm{Ga}_{\mathrm{x}-1}\right) \mathrm{Se}_{2}$, Crystal structure, Electron backscattering diffraction, Solar cell, Transmission electron microscopy

\section{INTRODUCTION}

As devices are miniaturized with thinner films, the electrical and magnetic properties of surfaces and interfaces in multi-layered semiconductors can affect the overall device performance (Lebedev, 2006). Therefore, it is vital to accurately analyze their interfacial properties. The absorber film adhesion and electrical properties rarely improve when they form alloys with adjacent layers (Würz et al., 2003); however, well defined epitaxial thin films are typically uniform with steady magnetic properties (Kousuke et al., 2011). High-resolution electron microscopy (HREM) is essential for nanoscale structural characterization and chemical composition. However, HREM provides restrictive nanoscale localized information. Recently, it has been reported that a technique of automated crystal orientation and phase mapp- ing, based on transmission electron microscopy (TEM) (similar to scanning electron microscope-electron backscatter diffraction [SEM-EBSD], TEM-EBSD), can analyze nanostructured materials for extensive structural information (Rauch et al., 2010; Moeck et al., 2011; Yoo et al., 2012). In this study, we applied a three-dimensional (3D) TEM-EBSD method to obtain more reliable structural information as a complement to energy dispersive spectroscopy (EDS) and HREM analysis combined with a tilting technique.

\section{EXPERIMENTAL METHODS}

In this study, a $\mathrm{Cu}\left(\mathrm{In}_{\mathrm{x}} \mathrm{Ga}_{\mathrm{x}-1}\right) \mathrm{Se}_{2}$ (CIGS) solar cell was used as the test sample as it has a complex crystal structure. The CIGS layer was deposited onto a Mo back electrode on top of a stainless steel substrate by co-evaporation at $500^{\circ} \mathrm{C}$,

This work was supported by the KBSI (Korea Basic Science Institute) grant to J.-G. Kim (T35210) and the NEW \& Renewable Energy R\&D program (20113020030020) under the Ministry of Knowledge Economy, Republic of Korea.

@ This is an open-access article distributed under the terms of the Creative Commons Attribution Non-Commercial License (http://creativecommons.org/licenses/by-nc/4.0) which permits unrestricted noncommercial use, distribution, and reproduction in any medium, provided the original work is properly cited.

Copyrights $\odot 2015$ by Korean Society of Microscopy 
and an epitaxial CdS layer was grown using a chemical bath deposition (Lee et al., 2013). A cross section TEM specimen was prepared by a focused ion beam (Quanta 3D FEG; FEI, USA). The lattice parameters and chemical analysis of the CIGS structure were determined by EDS (JED-2200; JEOL Ltd., Japan). HREM was analyzed using TEM (200 kV, JEM-2100F; JEOL Ltd.). TEM-EBSD (ASTAR; NanoMEGAS, Belgium) was used to analyze the crystal orientation distributions (nanobeam diffraction mode; spot size, $2.4 \mathrm{~nm}$; camera length, 30 $\mathrm{cm}$; step width, $2.4 \mathrm{~nm}$; scan area, $700 \times 500 \mathrm{~nm}$; acquisition time, 70 frames/s). Orientation imaging microscopy software (TSL OIM; EDAX Inc., USA) was used to extract the specific crystal orientation and phase map from the TEM-EBSD raw data.

\section{RESULTS AND DISCUSSION}

CIGS, a tetrahedrally bonded copper chalcopyrite structure, is composed of a variety of chemical compositions (Kaneshiro et al., 2010). To accurately analyze the crystal structure of CIGS, the crystallographic information of the CIGS structure must be quantified. EDS analysis was utilized to obtain the precise chemical information of the CIGS structure as the lattice parameters were varied along with the $\mathrm{Ga} /(\mathrm{In}+\mathrm{Ga})$ ratio. It was observed that the $\mathrm{Ga} /(\mathrm{In}+\mathrm{Ga})$ ratio of bulk region was higher than that of surface and its quantitative result was shown in Fig. 1. Ga/(In+Ga) ratio was calculated nearby surface area to acquire exact $\mathrm{Ga} /(\mathrm{In}+\mathrm{Ga})$ ratio of CIGS/ CdS interface, the final chemical composition of the surface structure was determined to be $\mathrm{Cu}\left(\mathrm{In}_{0.76} \mathrm{Ga}_{0.24}\right) \mathrm{Se}_{2}$. From these results, the $\mathrm{Cu}\left(\mathrm{In}_{0.76} \mathrm{Ga}_{0.24}\right) \mathrm{Se}_{2}$ lattice parameters were calculated using Vegard's rule (Vegard, 1921; Caro et al., 1998; Darakchieve et al., 2008), resulting in $\mathrm{a}=5.737 \AA$ and $\mathrm{c}=11.489$ $\AA$, and were used to analyze TEM-EBSD. CdS is known to have a hexagonal structure $\alpha$-CdS phase (wurtzite), a cubic structure $\beta$-CdS phase (zinc blende) or mixed phase of the two (Kaur et al., 1980; Najanishi et al., 1994; Zelaya-Angel et al., 1994). It is difficult to distinguish $\alpha$-CdS and $\beta$-CdS phases using conventional TEM analysis because of their similar d-spacing value. To accurately analyze the CIGS/CdS interface crystal structure, the crystallographic information of the CIGS and CdS structures must be quantified.

HREM images were used to analyze the interface structure between the CIGS and CdS layers. However, with HREM, the accurate zone axis could not be determined due to similar electron diffraction patterns (EDPs) including $[110]_{\mathrm{CIGS}}$ and $[201]_{\mathrm{CIGS}}$, as well as $[0001]_{\mathrm{h}-\mathrm{CdS}}$ and $[110]_{\mathrm{c}-\mathrm{CdS} \text {. To address this }}$ difficulty, a tilting technique was utilized to allow tracing of the various zone axes. Fig. 2 shows three HREM images of the CIGS and CdS crystal structures obtained using the specimen tilting technique. Fig. $2 \mathrm{~B}$ is the HREM image of the initial zone axis, with the white arrow in the inset image indicating the tilt axis. For the CdS layer, this can be indexed to both the cubic and hexagonal structures. However, the TEM used in this experiment was equipped with a narrow pole-piece gap, so the tilting angle was limited to approximately $\pm 25^{\circ}$. From the second and third tilting HREM images, the hexagonal structure of the CdS deviated from the mechanical tilting range because the interplanar angle between the $[\overline{2} 4 \overline{2} 3]_{\mathrm{h}-\mathrm{Cds}}$ and the $[4153]_{\mathrm{h}-\mathrm{Cds}}$ was $62.95^{\circ}$, revealing that the predominant CdS layer crystal structure was the cubic phase. Similarly, the CIGS structure's initial zone axes, [110] or [201], were transferred to the [310] or [601] directions (Fig. 2C), and then finally transferred to the [100] direction (Fig. 2D). To determine the exact zone axis of the CIGS structure, a fitting was performed between simulated EDPs and fast Fourier
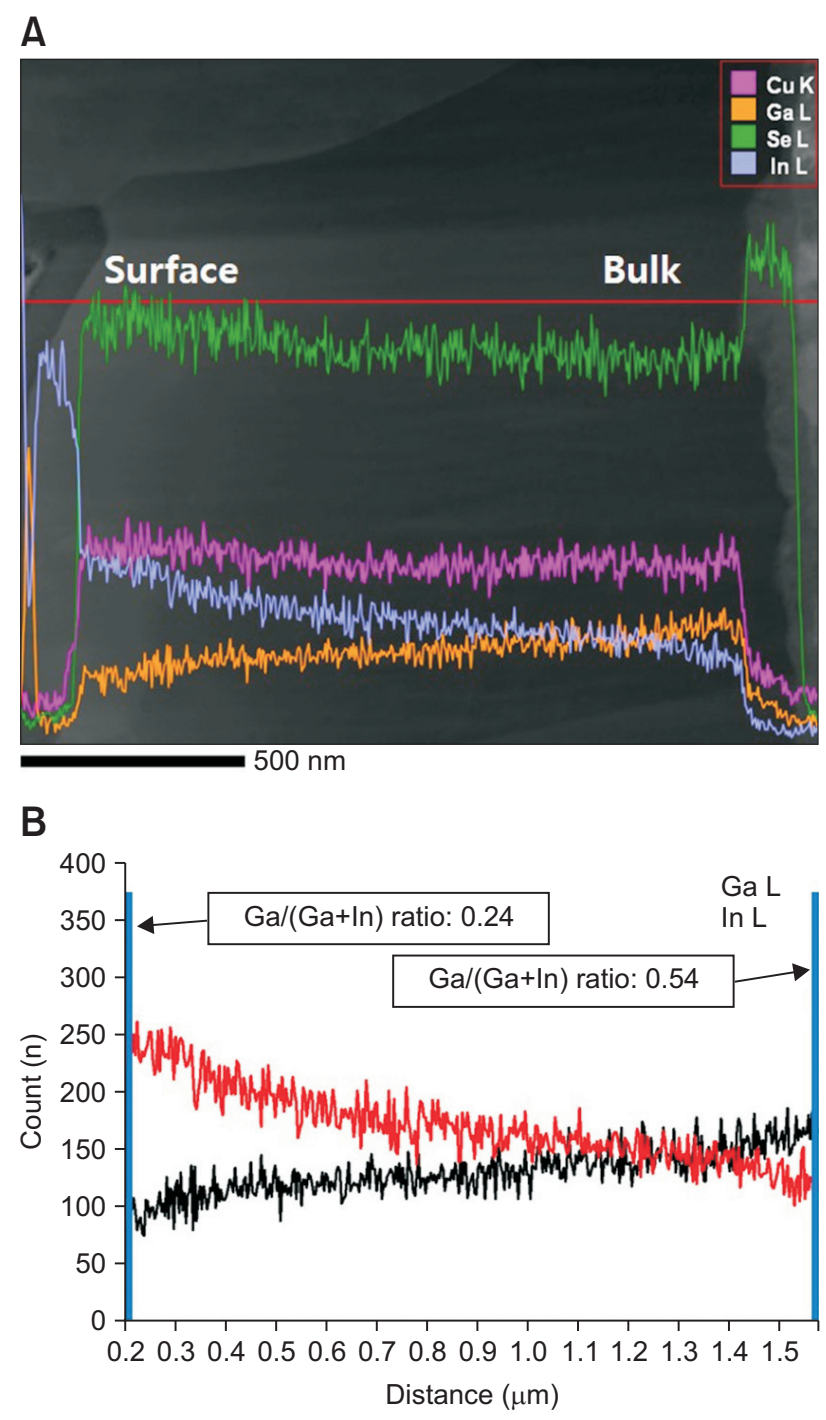

Fig. 1. Fig. 1A indicates the energy dispersive spectroscopy line profiles used to confirm the chemical composition of the $\mathrm{Cu}\left(\operatorname{In}_{\mathrm{x}} \mathrm{Ga}_{\mathrm{x}-1}\right) \mathrm{Se}_{2}$ layer. Fig. $1 \mathrm{~B}$ shows the $\mathrm{Ga} /(\mathrm{In}+\mathrm{Ga})$ ratio from the surface to the bulk region. 

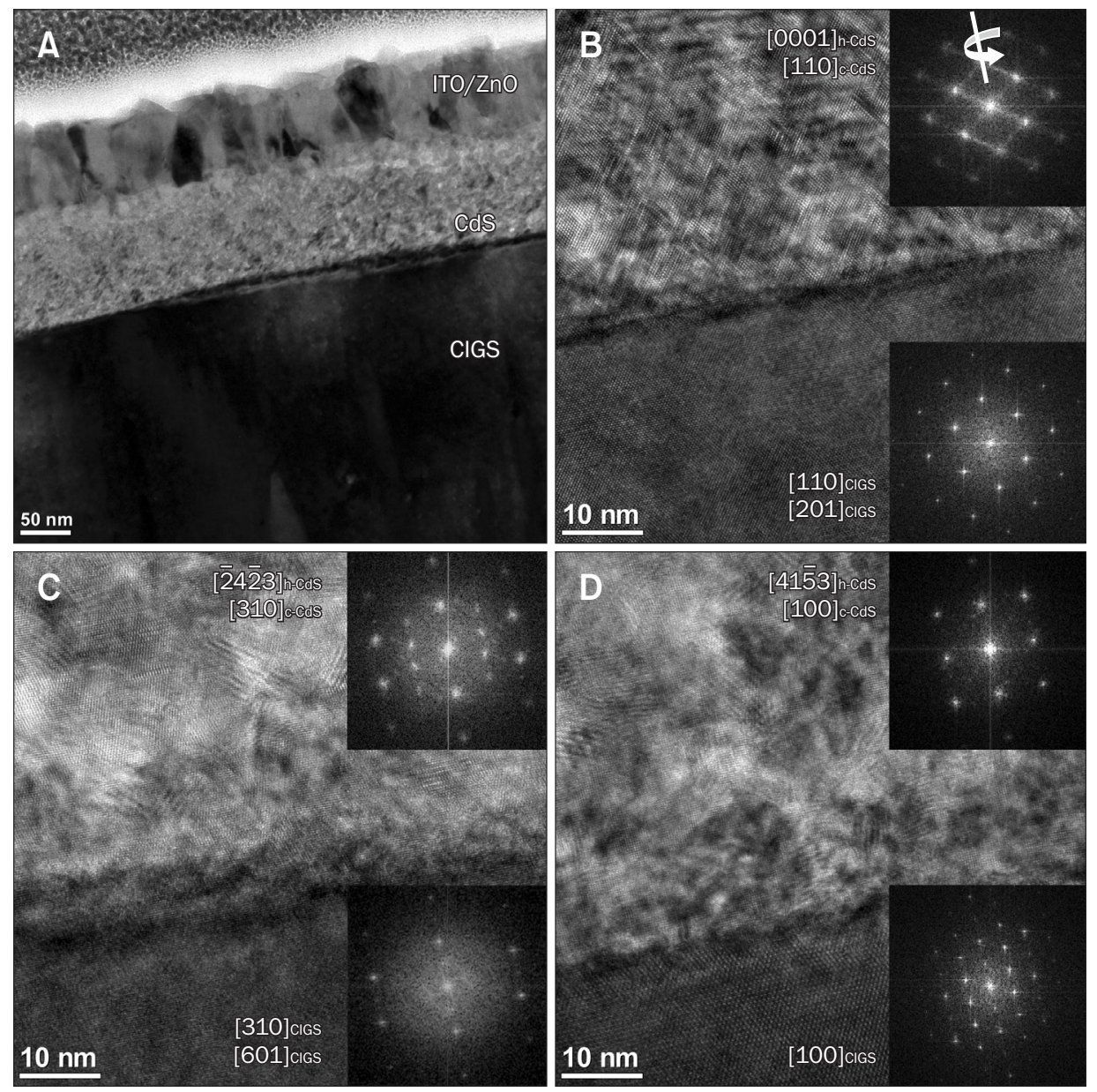

Fig. 2. (A) Bright field image of the $\mathrm{Cu}\left(\mathrm{In}_{\mathrm{x}} \mathrm{Ga}_{\mathrm{x}-1}\right) \mathrm{Se}_{2}$ (CIGS)/CdS interface. (BD) High-resolution images and their fast Fourier transform patterns (insets) of the CIGS/CdS interface using the specimen tilting technique.

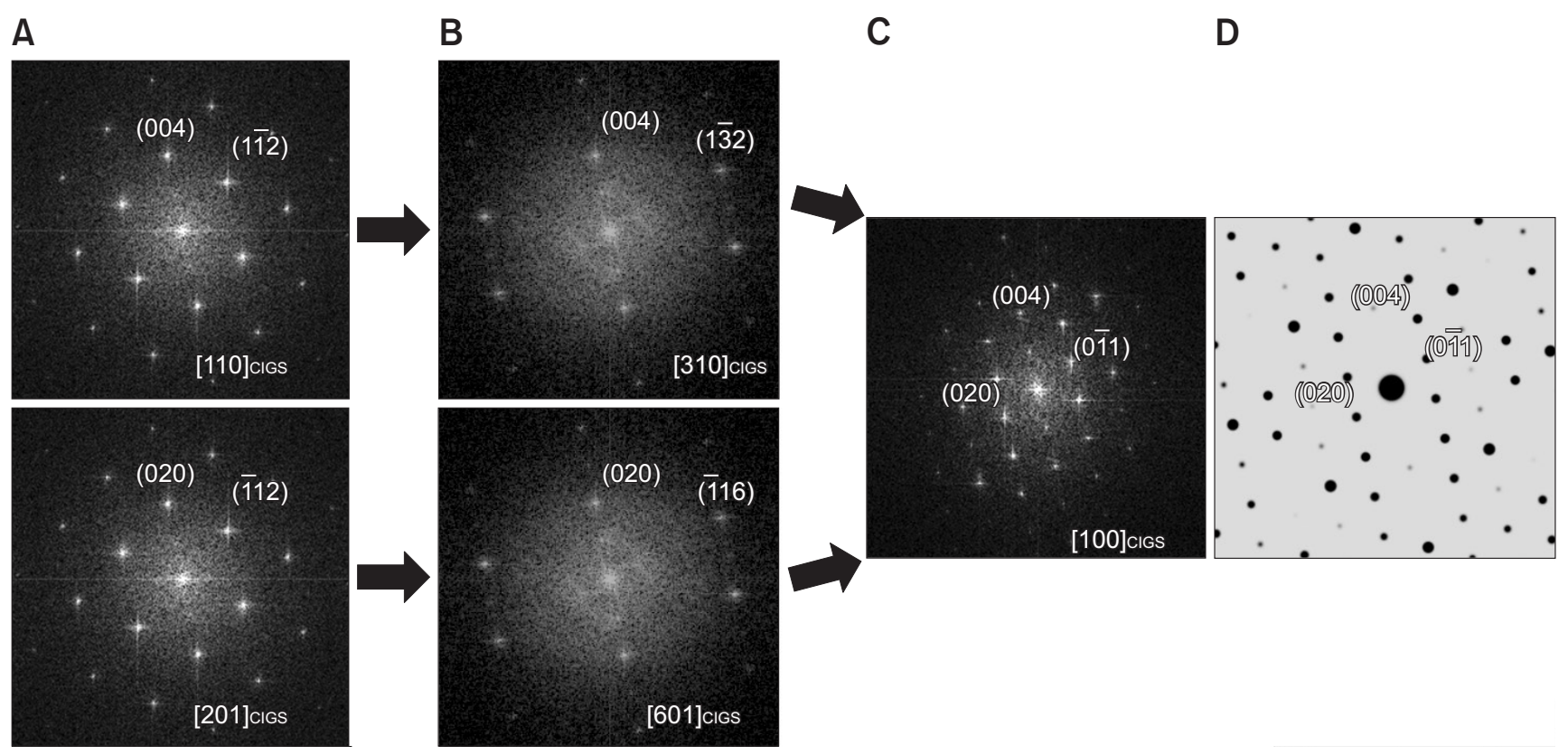

Fig. 3. Two different indexing results for the tilting series fast Fourier transform images of the $\mathrm{Cu}\left(\mathrm{In}_{\mathrm{x}} \mathrm{Ga}_{\mathrm{x}-1}\right) \mathrm{Se}_{2}$ (CIGS) crystal (A-C), and the simulated electron diffraction pattern of $[100]_{\text {CIGS }}(D)$. 
transform patterns of each HREM image (Fig. 3). The results demonstrated that the (004) reflection of the [110] zone axis was accurately maintained in the [110]-[310]-[100] tilting series process; whereas the (020) reflection of the [201] zone axis rotated $90^{\circ}$. Therefore, it could be determined that the CIGS crystal tilted from [110] to [310], and then to [100]. The HREM analysis utilizing the tilting technique can clearly obtain the accurate zone axes, thus demonstrating that the CIGS and CdS layers were deposited epitaxially on the nanoscale. To determine the physical properties of the CIGS solar cell, the dominant crystal structure of the CIGS/CdS interface below the microscale must be investigated.

A TEM-EBSD analysis was used to obtain a wide range of crystal structural information to enhance the HREM analysis reliability. The crystal orientation relationship at the CIGS/ CdS interface was identified using a 3D TEM-EBSD analysis
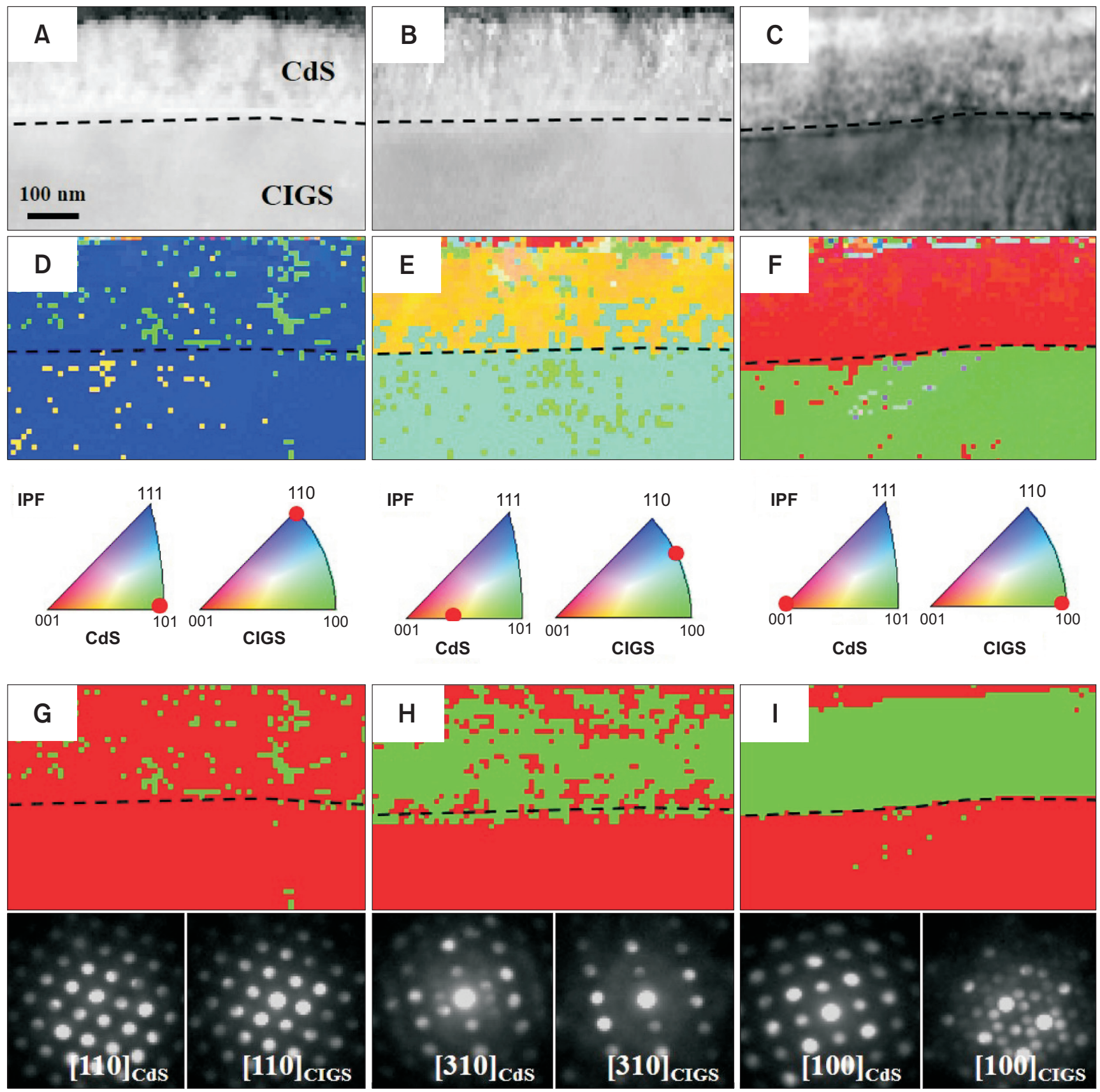

Fig. 4. (A-C) Virtual bright field images from transmission electron microscopy-electron backscatter diffraction at the $\mathrm{Cu}\left(\mathrm{In}_{\mathrm{x}} \mathrm{Ga}_{\mathrm{x}-\mathrm{I}}\right) \mathrm{Se}_{2}(\mathrm{CIGS}) / \mathrm{CdS}$ interface . (D-F) Crystal orientation and inverse pole figure (IPF) maps. (G-I) Phase maps (red, CIGS; green, CdS) and the nano-beam electron diffraction patterns. 


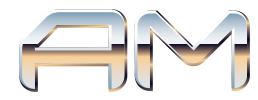

(Fig. 4). The observed area was shown through virtual bright field images (Fig. 4A-C). Their corresponding crystal orientation and phase maps are displayed in Fig. 4D-F and Fig. 4G-I, respectively. The bright field images confirmed that the crystallographic information of the CIGS/CdS interface was acquired at the same position. Each orientation and phase map of the CIGS/CdS interface across the three different zone axes was determined through computational matching of the experimental and simulated EDPs. The orientation map of the $[110]_{\mathrm{CIGS}} /[110]_{\mathrm{CdS}}$ is displayed with an overall blue color (Fig. 4D), and the phase map is displayed with overall red color (Fig. 4G), with neither layers clearly distinguished. This disproved that the CIGS EDPs were analogous to the CdS EDPs, and the $(002)_{\text {CdS }}$ was deposited parallel on the $(004)_{\text {CIGs }}$. The difference between the $\mathrm{d}$-spacing value in the $(002)_{\mathrm{CdS}}$ and $(004)_{\mathrm{CIGS}}$ is within $1.4 \%$, indicating that the $(002)_{\mathrm{CdS}}$ can be easily grown epitaxially on the $(004)_{\mathrm{CIGS}}$. Similar to the HREM analysis, it was difficult to segregate the two phases in the $[110]_{\mathrm{CIGS} \text { and CdS }}$ directions. Therefore, the sample's zone axis was changed from the first to the third tilting direction, allowing differentiation between the two structures. As a result, the crystallographic orientation and phase of the CIGS/CdS interface was clearly determined by analyzing the $[100]_{\mathrm{CIGS}} /[100]_{\mathrm{CdS}}$ interface region (Fig. $4 \mathrm{~F}$ and I). Consequently, 3D TEM-EBSD can identify the structural relationship between epitaxially grown layers through the successful extraction of orientation and phase information. As a result, the crystal orientation relationship was confirmed as $\left.\left.\langle 110\rangle_{\text {CdS }} / /<110\right\rangle_{\text {CIGS }},\langle 310\rangle_{\text {CdS }} / /<310\right\rangle_{\text {CIGS }}$ and $\left.\langle 100\rangle_{\text {CdS }} / /<100\right\rangle_{\text {CIGS }}$ in each zone axis. This result verifies that the CIGS/CdS interface formed epitaxially without an alloy phase, illustrating the usefulness of 3D TEM-EBSD for analyzing semiconductor interfaces.

\section{CONCLUSIONS}

The research of CIGS solar cell has proceeded substantially. Accordingly, it is important that their structural relation should be investigated in detail. Conventional TEM technique and SEM-EBSD technique are restricted to analyze crystal structure of multi-layer. But it was possible to analyze effectively CIGS/CdS interface using TEM-EBSD. Especially, the structural relationship of CIGS and CdS layer could be interpreted using TEM tilting technique. Therefore, TEMEBSD analysis can be a powerful tool to overcome limitation of SEM-EBSD (resolution and sample tilt) and to analyze orientation and phase mapping of multilayer structured materials. Furthermore, 3D TEM-EBSD can be considered a desirable tool to improve the solar-to-electricity efficiency of the CIGS solar cell device.

\section{CONFLICT OF INTEREST}

No potential conflict of interest relevant to this article was reported.

\section{REFERENCES}

Caro L D, Giannini C, Tapfer L, Schönherr H P, Däweritz L, and Ploog K G (1998) Validity of Vegard's rule for the lattice parameter and the stiffness elastic constant ratios of the AlGaAs ternary compound. Solid State Commun. 108, 599-603.

Darakchieve V, Beckers M, Xie M Y, Hultman L, Monemar B, Carlin J F, Feltin E, Gonschorek M, and Grandjean N (2008) Effects of strain and composition on the lattice parameters and applicability of Vegard's rule in $\mathrm{Al}$ rich $\mathrm{Al}_{1-x} \mathrm{In}_{x} \mathrm{~N}$ films grown on sapphire. J. Appl. Phys. 103, 103513-103517.

Kaneshiro J, Gaillard N, Rocheleau R, and Miller E (2010) Advances in copper-chalcopyrite thin films for solar energy conversion. Sol. Energy Mater. Sol. Cells 94, 12-16.

Kaur I, Pandya D K, and Chopra K L (1980) Growth kinetics and polymorphism of chemically deposited CaS films. J. Electrochem. Soc. 127, 943-948.

Kousuke T, Mitsuru O, Katsumasa N, and Masaaki F (2011) Preparation and characterization of $\mathrm{Co} / \mathrm{Pd}$ epitaxial multilayer films with different orientations. Jpn. J. Appl. Phys. 50, 073001-1-7.

Lebedev M V (2006) Interaction of the solvated hydrosulfide ions with GaAs surface at the semiconductor/electrolyte interfaces: chemical and electronic processes. In: Trends in Surface Science Research, ed. Norris C P, pp. 97-129, (Nova Science Publishers, New York).

Lee Y H, Kim K B, Kim J G, Park K B, Im W B, and Kim Y I (2013) Crystallographic study of CIGS solar cell module via structural refinement. J. Nanoelectron. Optoelectron. 8, 575-578.

Moeck P, Rouvimov S, Rauch E F, Véron M, Kirmse H, Häusler I, Neumann W, Bultreys D, Maniette Y, and Nicolopoulos S (2011) High spatial resolution semi-automatic crystallite orientation and phase mapping of nanocrystals in transmission electron microscopes. Cryst. Res. Technol. 46, 589-606.

Najanishi T and Ito K (1994) Properties of chemical bath deposited CdS thin films. Sol. Energy Mater. Sol. Cells 35, 171-178.

Rauch E F, Portillo J, Nicolopoulos S, Bultreys D, Rouvimov S, and Moeck P (2010) Automated nanocrystal orientation and phase mapping in the transmission electron microscope on the basis of precession electron diffraction. Z. Kristallogr. 225, 103-109.

Vegard L (1921) Die konstitution der mischkristalle und die raumfüllung der atome. Z. Phys. 5, 17-26.

Würz R, Marron D F, Meeder A, Rumberg A, Badu S M, Schedel-Niedrig T, Bloeck U, Schubert-Bischoff P, and Lux-Steiner M Ch (2003) Formation of an interfacial $\mathrm{MoSe}_{2}$ layer in CVD grown $\mathrm{CuGaSe}_{2}$ based 
thin film solar cells. Thin Solid Films 431-432, 398-402.

Yoo S J, Kim J G, Kim C Y, Kim E M, Lee J H, Kim Y M, Yoo S J, Kim S B, and Kim Y J (2012) Characterization of crystallographic properties of GaN thin film using automated crystal orientation mapping with TEM. Met. Mater. Int. 18, 997-1001.
Zelaya-Angel O, Alvarado-Gil J J, Lozada-Morales R, Vargas H, and Ferreira da Silva A (1994) Band-gap shift CdS semiconductor by photoacoustic spectroscopy: evidence of a cubic to hexagonal lattice transition. Appl. Phys. Lett. 64, 291-293. 